\title{
Morphoquantitative analysis of cloacal bursa in fowls (Gallus gallus domesticus, linnaeus, 1758) lineage master Gris cou plumé
}

\begin{abstract}
The functions of the cloacal bursa are not known in great detail; therefore, detailed morphophysiological studies are necessary to elucidate the relationship between this structure and the immunity of birds. A quantitative analysis was performed to determine the volume density of lymphocytes (Vv[lymphocytes]) and connective tissue density arranged along the organ. Cloacal bursa, from male and female Gallus gallus domesticus, aged between one and seven weeks old, were separated in seven groups according to age (G1 to G7). Histological sections were stained with hematoxilin-eosin and Picrosirius red to differentiate lymphocytes and connective tissue, respectively. Vv(lymphocytes) increased up to 4 weeks, decreasing in subsequent weeks. Connective tissue density increased throughout the seven weeks studied. Areas of intense lymphopoiesis were observed from G1 to G4 and areas of distancing between the cells and early tissue necrosis were observed from G5 to G7. Therefore, the increase in the lymphocytes number expected during the development and maturation periods of the cloacal bursa occurred in the first four weeks. From that period, the involution process started, lymphoid depletion was observed while connective tissue density increased. These processes occurred as simultaneous and inversely proportional events during the remodeling process of the organ. A bolsa cloacal apresentou alterações em sua constituição ao longo das sete semanas analisadas. As expected and described in literature, the main alterations observed were the lymphocyte depletion and the increasing in connective tissue density that did not follow a regular pattern, but occurred in simultaneous events and in a inversaly proportional way.
\end{abstract}

Keywords: lymphocytes, connective tissue, lymphoid, cells, necrosis
Volume 6 Issue I - 2017

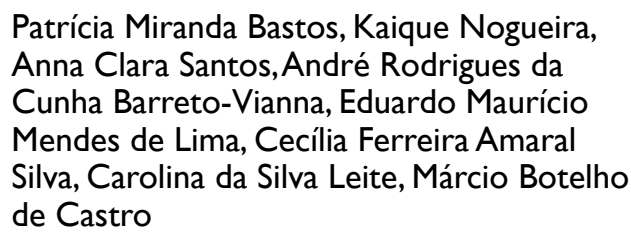

Department of Faculdade de Agronomia e Medicina Veterinária, Universidade de Brasília, Brazil

\section{Correspondence: Eduardo Maurício Mendes de Lima, Professor, Universidade de Brasília, Departamento de Medicina Veterinária , Distrito Federal, Brazil,Tel (6I)31072817,} Email limaemm@unb.br

Received:September 13, 2017 | Published: November 21, 2017

\section{Introduction}

The cloacal bursa is a specialized organ found in birds that is located between the cloaca and sacrum, dorsally to the proctodeum. ${ }^{1}$ It is considered a primary organ in the proliferation and diversification of $\mathrm{B}$ cells present in the medullary region of the organ from the fourteenth day of incubation. ${ }^{2}$ The cloacal bursa is composed of epithelial cells, dendritic cells, macrophages, some plasma cells, and lymphocytes. It is estimated that $98 \%$ of the bursa lymphocytes are B lymphocytes that proliferate both in the cortex and in the medullary region. B lymphocytes express IgM on their surface while MHC class II is expressed only in the cortical B cells. T cells can also be identified in the parenchyma of the organ; however, their concentration seems to depend on B cell depletion. ${ }^{1}$ The cloacal bursa development peaks in young animals between one and two weeks old, with high lymphopoiesis and further development of immune competence of lymphocytes that later move to secondary lymphoid organs. There is, then, gradual and slow cloacal bursa involution after this period. ${ }^{3}$

Despite the high standards required for health and feeding conditions, the poultry industry still faces problems related to immunosuppressive diseases such as infectious bursal disease. This disease is responsible for high mortality rates among young animals and has been causing economic losses to the poultry industry, both in Brazil and worldwide. ${ }^{4}$ Aflatoxicosis, Marek's disease, Avian
Infectious Anemia and Avian Influenza are other immunosuppressive diseases responsible for lymphoid depletion in the cloacal bursa, thymus, proventriculus, intestines, and kidneys. ${ }^{5}$ The functions of the cloacal bursa are not known in great detail, and it is necessary to further study the bursa morphology and physiology in order to elucidate the relationship between this structure and the immunity of the birds. Thus, the objective of this stuDY was to determine, through quantitative analysis, the density of lymphocytes and connective tissue in the cloacal bursa during the first seven weeks of life.

\section{Materials and methods}

A total of 21 male and female broiler chickens (Gallus gallus domesticus) of the Master Gris Cou Plumé lineage were used. The age of the birds varied between one to seven weeks old, and they were separated in seven groups of three animals each, according to age, as follows: 1week (G1), 2weeks (G2), 3weeks (G3), 4weeks (G4), 5weeks (G5), 6weeks (G6), and 7weeks (G7). The study was approved by the Ethics Committee on Animal Use of the Universidade de Brasilia (\# 50607/2013). Euthanasia was performed under deep anesthesia (halothane, Cristália Laboratory). Subsequently, the cloacal bursa of the animals was collected and fixed in $10 \%$ formaldehyde solution for about 72 hours. Following, four fragments from each cloacal bursa were randomly sectioned and submitted to conventional histological technique. Samples were fixed in $10 \%$ formaldehyde for about 
72hours and embedded in paraffin. After that it was sliced at $4 \mu \mathrm{m}$ in manual microtome. Four slides were prepared for each fragment, which were stained with hematoxylin-eosin and Picrosirius $\operatorname{Red}^{6}$ to identify the lymphocytes and determine the connective tissue density, respectively.

The volume density ( $\mathrm{Vv}$ ) of lymphocytes was determined by the digital point counting system using the STEPanizer(C 1.0 software. The connective tissue density in the images was performed by segmentation using the Image ProPlus $6.0 \AA$ software. An optical microscope Leica, with polarized lenses and image analysis ProRes CaputrePro $2.5 \AA$ software was used. Data were examined for normality using the GraphPad Prism ${ }^{\circledR}$ software (version 4.00 for Windows, GraphPad Software, San Diego, CA, USA) and were demonstrated as mean and standard deviation. Following descriptive statistics analysis, the one-way ANOVA test was applied. Differences were considered statistically significant when $\mathrm{P}<0.05$.

\section{Results}

Density of lymphocytes did not change uniformly over the evaluation period, showing an increase up to four weeks, followed by a decrease in subsequent weeks. On the other hand, the density of connective tissue increased over the seven-week period (Table $1)$. The volume density of lymphocytes had a significant increase of $26 \%(\mathrm{p}<0.05)$ between G1 and G4. On the other hand, it decreased $57.6 \%$ between G4 and G5. Therefore, the Vv(lymphocytes) had a significant decrease of $39.8 \%$ between the first (G1) and seventh (G7) weeks $(\mathrm{p}<0.05)$ (Figure 1A, Table 1). Unlikely, the connective tissue density increased significantly during the experiment, $59.2 \%$ between G1 and G7 $(\mathrm{p}<0.05)$ (Figure 1B, Table 1).

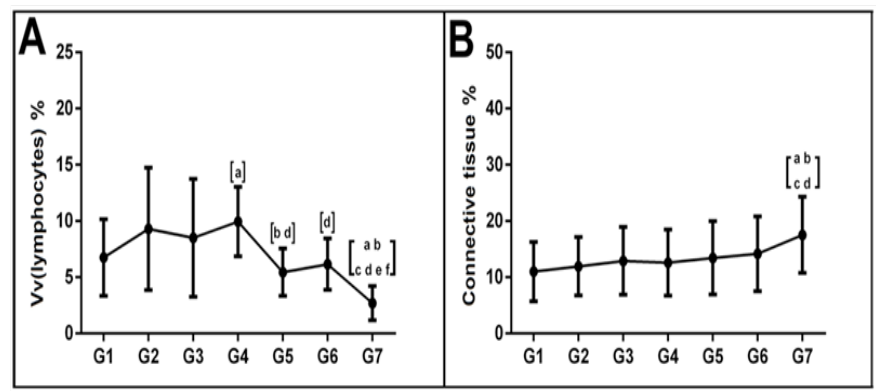

Figure I Density of lymphocytes and connective tissue in evaluation period.

Comparison between $\mathrm{Vv}$ (lymphocytes) and connective tissue among then, in each group, shows statistical difference $(p<0.05)$ in all groups Figure 2. Connective tissue density and time were strongly and positively correlated according to the Spearman correlation test $(\mathrm{r}=0.96)$, that is, connective tissue density increased significantly over time ( $\mathrm{p}=0.003)$ (Figure 2). Correlation between the two densities was moderate and negative $(\mathrm{r}=-0.77)$, showing that as the volume density of lymphocytes decreased, the connective tissue density increased Figure 2, although not statistically significant $(\mathrm{p}=0.08)$ (Table 2). Photomicrographs analysis Figure 3 showed areas with high lymphocyte concentration (Figure 3A), characterizing stages of cell development/maturation, especially in the cortical region of cloacal bursa. The quantitative analysis of that week (Table 1) corresponded with histopathologic findings. In contrast, there was a large spacing between the cells and consequent decrease of lymphocyte density in G7 (Figure 3B). Besides the change in lymphocyte density, the beginning of parenchymal liquefactive necrosis was also observed in G5 (Figure 3C). The necrotic degree was advanced in G7, and it was possible to observe increased cell spacing and difficulty to distinguish between the cloacal bursa cortical and medullary regions (Figure $3 \mathrm{D})$. It was possible to observe the evolution of the connective tissue density from G1 (Figure 3E) to G7 (Figure 3F).

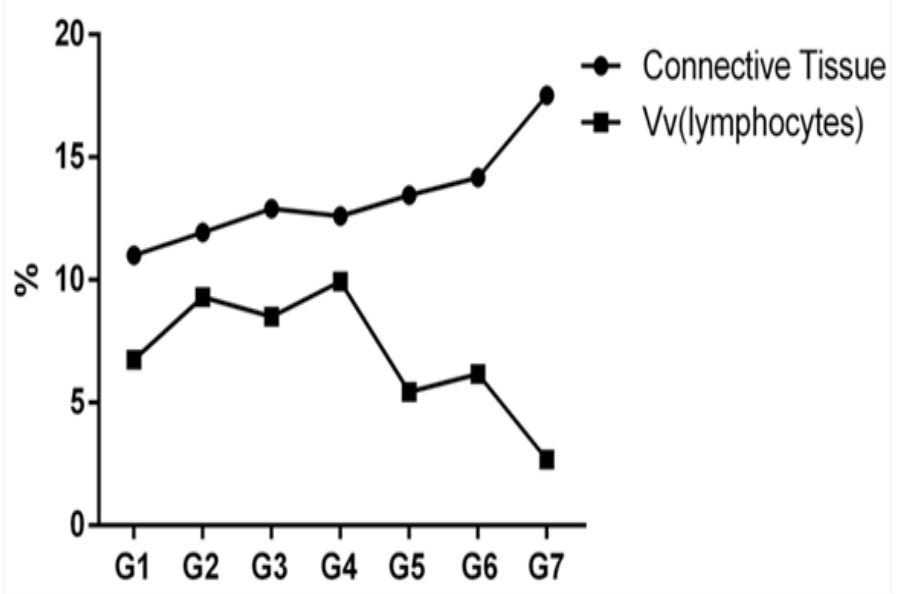

Figure 2 Statistical difference of lymphocytes and connective tissue.

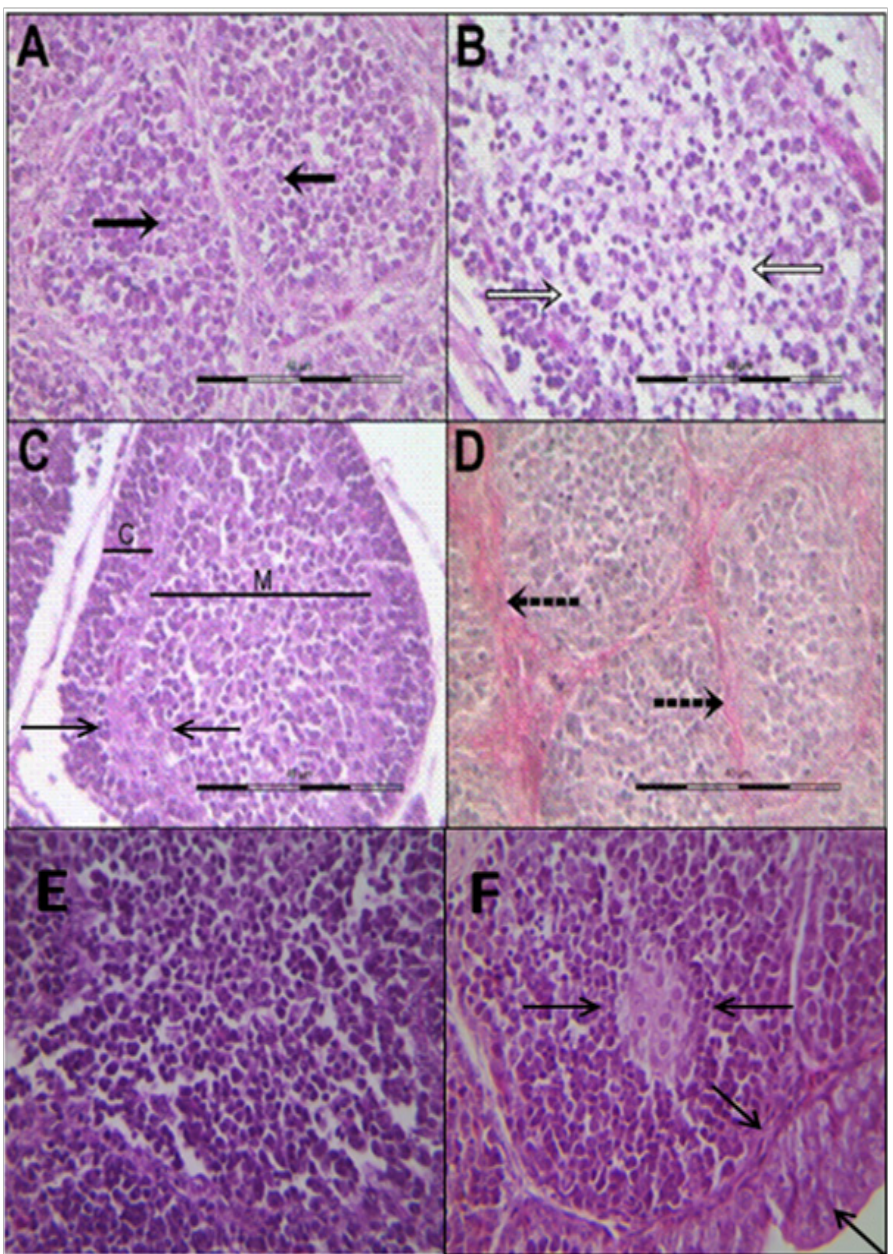

Figure 3 Photomicrographs analysis. 
Table I Means and standard deviation values for the volume density of lymphocytes and connective tissue in the Gallus gallus domesticus cloacal bursa from one to seven weeks, followed by the respective $p$-values of the normality test

\begin{tabular}{lll}
\hline Group & $\mathbf{V v}($ Lymphocytes $) \%$ & Connective tissue density\% \\
\hline 1 & $6.75 \pm 0.56(p=0.07)$ & $11.0 \pm 0.88(p=0.02)$ \\
2 & $9.31 \pm 0.90(p=0.09)$ & $11.95 \pm 0.86(p=0.08)$ \\
3 & $8.50 \pm 0.87(p=0.08)$ & $\mid 2.91 \pm 1.00(p=0.20)$ \\
4 & $9.94 \pm 0.51(p=0.01)$ & $\mid 2.60 \pm 0.98(p=0.01)$ \\
5 & $5.44 \pm 0.35(p=0.01)$ & $\mid 3.46 \pm 1.08(p=0.20)$ \\
6 & $6.17 \pm 0.38(p=0.20)$ & $\mid 4.17 \pm 1.11(p=0.20)$ \\
7 & $2.69 \pm 0.25(p=0.01)$ & $\mid 7.53 \pm 1.13(p<0.01)$ \\
\hline
\end{tabular}

Table 2 R-values for the spearman correlation test. ${ }^{*} \mathrm{p}<0.05$

\begin{tabular}{lll}
\hline & $\mathbf{V v}($ Lymphocytes) & Connective tissue density \\
\hline Week & -0.64 & $0.96^{*}$ \\
$\operatorname{Vv}($ lymphocytes $)$ & - & -0.71 \\
\hline
\end{tabular}

\section{Discussion}

The involution of the cloacal bursa can occur physiologically or chemically, and in the latter case, it is stimulated by administration of exogenous substances, such as cyclosporine in premature stages of incubation. ${ }^{7}$ Before the physiological involution, two other periods were related and classified as evolution and maturation stages, ${ }^{3}$ as also recorded in the results of this study. Concerning the developing of the cloacal bursa, its parenchyma can be modified according to temperature. Ciricao $\mathrm{E}^{8}$ reported that boilers from Aviam Farms lineage subjected to heat showed a faster development of the parenchyma of the cloacal bursa during the first two weeks of age. Otherwise, the same authors observed a slower development of the parenchyma of the organ when it was submitted to cold, also characterizing an increasing on cellular apoptosis in cloacal bursa with consequent depletion on lymphoid tissue. ${ }^{8}$ The development of the cloacal bursa, and consequently its lymphocyte concentration, peaks in young animals between one and two weeks, followed by involution from then onward, ${ }^{9}$ while in embryo chicks from White Leghorn lineage ${ }^{10}$ and in ostrich embryos, ${ }^{11}$ the lymphocytes are less developed in this period. Unlike the findings in the literature, in this study, the lymphocyte concentration peaked in the fourth week (G4) when the birds were 4 weeks old. At its peak, average lymphocyte density was $9.94 \%$. Following the fourth week, lymphocyte density decreased unsteadily until the seventh week, to an average $2.69 \%$. Some authors claim that the involution starts only from the $12^{\text {th }}$ week while others state that regression is evident from the $12^{\text {th }}$ week and on, but it begins before this time. ${ }^{9}$

There are evidences that the growth hormone, also produced by the cloacal bursa in birds, could be responsible for the organ maturation and involution, since this hormone may be involved in the modulation of apoptosis. ${ }^{12}$ This fact may explain the initial liquefactive necrosis in the cloacal bursa medullary region, the progressive proliferation of connective tissue, and the progressive reduction of lymphocyte density observed in this study from the fourth week. It is known that $98 \%$ of the cloacal bursa lymphocytes from domestic birds are lymphocytes B and they proliferate both in the cortex and medulla of this organ, while lymphocytes $\mathrm{T}$ are dispersed on cloacal bursa cortex and its density in the medullary portion is low. ${ }^{1}$

The lymphocytes and connective tissue densities were also correlated, as the lymphocyte concentration decreased, the connective tissue density increased over time when comparing the results between the weeks. The lymphocyte peaked in the fourth week of life, coinciding with a small drop in the connective tissue increasing rate that had occurred in the same week. Still, the peak of the connective tissue density was observed to coincide with the lowest average lymphocyte density. The increased density of connective tissue over the weeks suggests that the lymphoid tissue is being replaced by the connective tissue, as described by Marinho $\mathrm{CE}^{4}$ reported, in boiler chickens submitted to thermal stress, scarce cellularity similar to the findings of the present study, characterizing as wide void spaces between the cells (Figure 3B).

The outlook for the next few weeks following the seventh week is that a condensation occurs between the lymphoid follicles from the cortical and medullary region, making it difficult to distinguish between the two area. ${ }^{3}$ In addition, atrophy and epithelial degeneration, sub epithelial fibrosis, necrosis of cortical cells, macrophages infiltration in areas occupied by necrotic follicles and, finally, a complete fibrous organization $^{3,9}$ are expected as well. ${ }^{13}$

\section{Conclusion}

The cloacal Bursa showed changes in its constitution along the seven weeks analyzed. As expected and described in literature, the main changes observed were the lymphocytic depletion and the increase in the connective tissue, not following a regular pattern, but occurring in at concurrent events and inversely proportional.

\section{Acknowledgements}

None.

\section{Conflict of interest}

Author declares that there is no conflict of interest.

\section{References}

1. Davison F, B kaspers, schatw. Avian Immunology. 1st ed. B cells, the Bursa of Fabricius and the generation of antibody repertories. USA: Elsevier; 2008.

2. Ekino S, Harakawa, Sonoda K, et al. The origin of IgG-containing cells in the bursa of Fabricius. Cell Tissue Research. 2012;348:537-550.

3. Abbate F, P farrer, C Jones, et al. Age-dependent changes in the pigeon bursa of Fabricius vasculature: a comparative study using light microscopy and scanning electron microscopy of vessel casts. Anatomical Society of Great Britain and Ireland. 2007;211(3):387-398.

4. Marinho CE, MJB Fernandes, IC Simoni. Estudo do ciclo de replicação do vírus da doença infecciosa das bursas de galinha na linhagem celular RK-13. Arquivo do Instituto Biológico. 2003;(70):5-9

5. Moraes LB, FS Osorio, FO Salle, et al. Evaluation of follicular lymphoid depletion in the Bursa of Fabricius: An alternative methodology using digital image analysis and artificial neural networks. Pesquisa Veterinária Brasileira. 2010;30:340-344.

6. Limac EMM, MIS Santana MB Castro, PP Bombonanto, et al. Quantificação de tecido conjuntivo do músculo cardíaco em equinos de tração através de técnicas histoquímicas e morfométricas. Ciência Rural. 2011;41(6):1030-1035 
7. Milicecvi Z, Zivanovic V, Milicivic NM. Anatomia, Histologia, Embryologia (31) Involution of Bursa cloacalis (Fabricii) and thymus in cyclosporin. A-treated chickens. 2002;31(1):61-64.

8. Ciricao E, PP Pinera, BD Esnal, et al. Age-Related Changes in the Avian Primary Lymphoid Organs (Thymus and Bursa of Fabricius). Microscopy research and technique. 2003;62(6):482-487.

9. AbbateF, C Pfarrer, CJP Jones, et al. Age-dependent changes in the pigeon bursa of Fabricius vasculature: a comparative study using light microscopy and scanning electron microscopy of vessel casts. Journal of Anatomy. 2007;211(3):387-398.

10. Ackermanna GA. Electron microscopy of the bursa of Fabricius of the embryonic chick whit particular reference of the limpho-epitelia nodules. Journal of Cell Biology 1962;13(1):127-146.
11. Song H, Peng KM, Wang Y, et al. Morphological characterization of the immune organs in ostrich chicks. Turkish Journal of Veterinary and Animal Sciences. 2012;36(2):89-100.

12. Luna M, Barraza N, Berumen L, et al. Heterogeneity of growth hormone immunoreactivity in lymphoid tissues and changes during ontogeny in domestic fowl. General and comparative endocrinology. 2005;144(1):28-37.

13. Guimares EB, Vasconcelas AC, MartinsNRS, et al. Parenchymal percentage and apoptotic index of cloacal bursa of broiler chickens maintained in thermal comfort or stress. Arquivo Brasileiro de Medicina Veterinária e Zootecnia. 2003;55(2):178-186. 